\title{
CHARACTERIZATION OF NANOCURCUMINOID FROM ETHANOL EXTRACT OF Curcuma Xanthorrhiza RHIZOME LOADED BY CHITOSAN AND ALGINIC AND ITS ANTIOXIDANT ACTIVITY TEST
}

\author{
S. Atun ${ }^{1, *}$, Y. Dewi ${ }^{1}$ and N. Aznam ${ }^{1}$ \\ ${ }^{1}$ Department Chemistry Education, Faculty of Mathematics and Natural Science, \\ Universitas Negeri Yogyakarta, INDONESIA \\ Jl. Colombo No.1 Depok, Sleman, Yogyakarta, 55281, Indonesia \\ E-mail: sriatun@uny.ac.id
}

\begin{abstract}
Curcuminoid is the main compound found in the Curcuma xantorrhiza rhizome. C. xantorrhiza plant which in Indonesia is known as temulawak is an herbal plant that is traditionally used to cure hepatitis, increase stamina, and as an anti-cholesterol. To enhance the stability, solubility and activity of the curcuminoid, should be developed into a product nanoparticle. The purpose of this study was to characterize nanocurcuminoids from ethanol extracts from the C. xantorrhiza rhizome loaded by chitosan and alginic acid, and its antioxidant activity test. The nanocurcuminoid formulation method uses ionic gelation. Chitosan nanocurcuminoid is made by mixing curcuminoid solution and chitosan solution, then adding sodium tripolyphosphate (Na-TPP). Meanwhile, alginic nanocurcuminoids are made by mixing a solution of curcuminoids and alginic acid solutions, which are then added to calcium ions. The activity of the nanocurcuminoid products obtained was tested as an antioxidant activity by the DPPH method (2,2-diphenyl-1-picrylhydrazyl). The results showed that chitosan nanocurcuminoid can be obtained in the addition of chitosan and sodium tripolyphosphate having a particle size of 251.8 to $874.3 \mathrm{~nm}$, polydispersion index (PI) 0.104 to 0.376 , with a zeta potential of +19.4 to $+30.8 \mathrm{mV}$. Alginic nanocurcuminoid can be formulated in the addition of alginic acid and calcium chloride having a particle size range of 161.6 to $210 \mathrm{~nm}$, PI 0.115 to 0.444 , with a zeta potential of -12.8 to $-27.8 \mathrm{mV}$. The morphology of nanocurcuminoid particle products was a spherical surface. Chitosan nanocurcuminoid and alginic nanocurcuminoid showed higher antioxidant activity than original curcuminoid.
\end{abstract}

Keywords: Alginic Canocurcuminoid, Antioxidant, Chitosan Nanocurcuminoid, Curcuma xanthorrhiza

(C) RASĀYAN. All rights reserved

\section{INTRODUCTION}

Nowadays, the use of nanotechnology has been applied in various fields such as electronics, energy, medicine, food, chemical sensors and molecular manufacturing. The particle size in the nanoscale is 1$1000 \mathrm{~nm}$, so it will have specific physical, chemical and biological characteristics. The use of nanotechnology in the medical field focuses on the application of technology in rapid diagnosis, drug administration, imaging, and therapy. Nanoparticle-based drug delivery systems have made a very interesting difference in studies using chemotherapy agents. Several nanoparticle products have been developed and used clinically ${ }^{1,2}$. The use of nanotechnology in the discovery of cancer drugs shows that it can reduce normal cell damage, increase absorption and distribution so that cancer drugs can work more optimally ${ }^{3}$.

The basic principles of making nanoparticles include nanoemulsion, dendrimers, nano-gold, liposomes, conjugated drug carriers, antibody complexes, and magnetic nanoparticles, mainly based on the use of raw materials of synthetic compounds, natural or biological compounds, metal ions, oils and fats as carriers. However, the potential success of these products in clinical trials depends on the consideration of important parameters such as nanoparticle fabrication strategies, efficient use of drugs, the potential for drug release, and most importantly, has a low level of toxicity ${ }^{4}$. Some cancer drugs have been made in the

Rasayan J. Chem., 13(1), 817-825(2020)

http://dx.doi.org/10.31788/RJC.2020.1325680

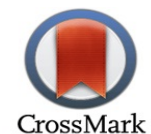


RASĀYAN J. Chem.

Vol. 13 | No. 2 |817 - 825| April - June | 2020

form of nanoparticles and have been approved by the FDA (Food and Drug Administration), for example, Abraxane is a breast cancer drug that is bound to albumin which has a particle size of $130 \mathrm{~nm}$ (FDA approved) in 2005). Doxil is also an ovarian cancer drug in the form of lipid nanoparticles with polyethylene glycol (PEG). Likewise, Tricor which is a cholesterol-lowering drug in the form of colloidal nanocrystals (FDA approved in 2004) . $^{5}$.

Some natural polymers such as chitosan, alginic, albumin, and gelatin have biodegradable and biocompatible properties. The materials are widely used as a matrix for the manufacture of nanoparticles. Chitosan is a natural polysaccharide consisting of $[\beta(1 \rightarrow 4)$ glucosamine (2-amino-2-deoxy-d-glucose) and N-acetyl-D-glucosamine (2-acetamin-2-deoxy-d-glucose)]. Chitosan is widely used in the pharmaceutical, food and health industries. Some of the beneficial properties of chitosan are antimicrobial, non-toxic, biocompatible, easily biodegradable, water-soluble, and relatively inexpensive 5 . Chitosan nanoparticles can avoid the use of organic solvents and prevent damage to the active ingredients of the drug. Therefore chitosan is widely used as a good drug delivery agent ${ }^{6}$. Likewise, alginic is a linear polysaccharide consisting of (1-4) $\alpha$-L-guluronic and $\beta$-D-mannuronic bonds. Alginic is mucoadhesive, biodegradable and biocompatible. Micro and alginic nanoparticles can be obtained easily by inducing gelation with calcium ions. This is an easy gel that can be used to produce pre-gels consisting of aggregates which are very small gel particles. The polyelectrolyte complex layer can be formed by the addition of polycationic solutions such as Poly-L-Lysine?

Curcuma xantorrhiza is an herbal plant that is widely available in Indonesia, known locally as temulawak. These herbs are traditionally used to cure hepatitis, increase stamina, anti-hemorrhoids, and anti-cholesterol $^{8}$. Curcuminoid extract from C. xanthorrhiza consists of curcumin and demethoxycurcumin ${ }^{9}$. Several studies exploring the pharmacological effects of curcuminoid compounds extracted from the Zingiberaceae family show typical anticancer properties ${ }^{10 ; 1 ; 12}$, anti-inflammatory ${ }^{13}$, anti-osteoarthritis ${ }^{14}$, anti-alzheimer ${ }^{15}$, immuno-stimulatory activity ${ }^{16}$, anti-cholesterol, and triglyceride ${ }^{17}$;

${ }^{18}$. Research related to the absorption, distribution, metabolism and excretion of curcuminoid, reveals that curcuminoid is difficult to absorb and is very quickly metabolized by the body thereby limiting biological availability ${ }^{19}$. Research shows that curcumin made into nanoparticles can increase its therapeutic potential. The results showed that curcuminoid in the form of nanoparticles with poly (butyl) cyanoacrylate was more stable for acidic conditions and did not experience damage in storage for up to 6 months ${ }^{20}$. Likewise, curcuminoid in the form of solid lipid nanoparticles shows better stability ${ }^{21}$. Some nanocurcuminoid formulation methods that can be performed include ionic gelation method, emulsification method, coacervation or precipitation method, and spray drying method ${ }^{5}$. The ionic gelation method involves cross-linking between polyelectrolytes and the presence of multivalent ion pairs. Ion gelation is usually done by forming a polyelectrolyte complex with other polyelectrolytes that have opposite charges. The formation of a crosslinker will strengthen the mechanical strength of the particles formed. Polymer nanoparticles are usually made using biodegradable and hydrophilic polymers such as chitosan, gelatin and alginic.

In this study, nanocurcuminoid formulations were carried out by the ionic gelation method using chitosan and alginic acid. Curcuminoid was obtained from the ethanol extract of $C$. xanthorrhiza. Chitosan nanocurcuminoid is made by putting curcuminoid into the chitosan solution, then adding sodium tripolyphosphate (Na-TPP). Meanwhile, alginic nanocurcuminoids are made by inserting curcuminoid into the alginic acid solution and adding calcium ions. Chitosan is a positively charged polymer of an amino group, while alginic acid is a negatively charged polymer of a carboxyl group. Chitosan will form a crosslinked polymer with tripolyphosphate ion, while alginic will crosslink with calcium ions. Furthermore, curcuminoids will be trapped inside the crosslinked polymer matrix.

\section{Apparatus and Reagents}

\section{EXPERIMENTAL}

Equipment used in this study includes glassware, digital analytical scales, evaporator Buchi Rotavapor R114, magnetic stirrers, centrifuges, refrigerators, spectronic 20 (Genesys), scanning electron microscopy (SEM, Jeol T-300), FTIR Shimadzu Prestige 21, and analytical equipment particle size (PSA), polydispersion index (PI), and zeta potential using Horiba SZ-100.The materials used include ethanol, 
RASĀYAN J. Chem.

Vol. 13 | No. 2 |817 - 825| April - June | 2020

aquabidest, chitosan (low molecular weight, Sigma), sodium tripoliphosphate (Na-TPP, Sigma-Aldrich), acetic acid (pa Sigma), alginic acid (pa Sigma), calcium chloride (pa Sigma), curcuminoid extract from $C$. xanthorrhiza, 2,2-diphenyl-1-picrylhydrazyl (DPPH, Aldrich), and ascorbic acid (Aldrich). The material is used in this work without further purification.

\section{Preparation of Curcuminoid Fraction from C. xanthorrhiza}

A total of C. xanthorrhiza powder $(1 \mathrm{~kg})$ was extracted by maceration with ethanol for 24 hours at room temperature, so extracts were obtained. The ethanol extract was then fractionated with $n$-hexane to remove the essential oil content, lipid or non-polar components, and then partitioned with chloroform to obtain yellow to orange solids from the curcuminoid fraction. The curcuminoid fraction is dried under vacuum and used for further experiments.

\section{Preparation of Chitosan Nanocurcuminoid}

Chitosan nanocurcuminoid formulation was carried out using the ionic gelation method. This method was chosen because it does not require heating, so the active compound is not damaged. In this ionic gelation method, it uses sodium tripolyphosphate as a crosslinking of chitosan particles to form a nanoparticlesized matrix, so that the curcuminoid gets trapped into the pores of the nanoparticle. Curcuminoid $(0.1 \mathrm{~g})$ is dissolved in $10 \mathrm{~mL}$ ethanol and $40 \mathrm{~mL}$ water. After the homogeneous solution is followed by the addition of $30 \mathrm{ml}$ of chitosan at various concentrations $(0.1 ; 0.08 ; 0.06$; and $0.04 \% \mathrm{w} / \mathrm{v}$ in $1 \%$ acetic acid) while mixed with a magnetic stirrer until homogeneous. The resulting solution was then added with $100 \mathrm{~mL} \mathrm{Na}$-TPP at various concentrations $(0.01 ; 0.015 ; 0.02 \% \mathrm{w} / \mathrm{v}$ in aquadest). The mixture is then stirred with a magnetic stirrer at medium speed for 2 hours. The mixture obtained is stabilized overnight in the refrigerator. Chitosan nanocurcuminoids in the form of colloids are then analyzed in terms of particle size, polydispersity index, and zeta potential. Next to obtain nanocurcuminoid in the form of solids is carried out by centrifugation at $12,000 \mathrm{rpm}$ for 15 minutes. The precipitate is washed with distilled water repeatedly and dried with a freeze dryer. Characterization of nanocurcuminoid solid products using IR spectroscopy, and SEM (Scanning Electron Microscopy).

\section{Preparation of Alginic Nanocurcuminoid}

Curcuminoid from C. xanthorrhiza $(0.1 \mathrm{~g})$ was dissolved in $10 \mathrm{ml}$ of ethanol and $40 \mathrm{~mL}$ distilled water until homogeneous. The solution was added with $30 \mathrm{~mL}$ of alginic acid at various concentrations $(0.1$; $0.08 ; 0.06$; and $0.04 \% \mathrm{w} / \mathrm{v}$ in $0.1 \mathrm{M} \mathrm{NaOH}$ ), while stirring using a magnetic stirrer until it was homogeneous. The mixture was then added with a solution of calcium chloride at various concentrations $(0.01 ; 0.015$; and $0.02 \% \mathrm{w} / \mathrm{v})$ while stirring with a magnetic stirrer at medium speed for 2 hours. The mixture was stabilized overnight in the fridge. Alginic nanocurcuminoid in the form of colloids are then analyzed in terms of particle size, polydispersity index, and zeta potential. Next, to obtain alginic nanocurcuminoid in the form of solids is carried out by centrifugation at 12,000 rpm for 15 minutes. The precipitate is washed with distilled water repeatedly and dried with a freeze dryer. Characterization of alginic nanocurcuminoid solid products using IR spectroscopy, and SEM (Scanning Electron Microscopy).

\section{Biological Activity As An Antioxidant}

Determination of the antioxidant activity of nanocurcuminoid products using the DPPH (2,2-diphenyl-1picrylhydrazyl) method ${ }^{22,23}$. In this method, DPPH functions as a source of free radicals. Each colloidal nanocurcuminoid is taken about $5 \mathrm{~mL}$ mixed with $5 \mathrm{ml}$ of DPPH methanol solution $(0.12 \mathrm{mM})$ and stored in the dark at room temperature for 30 minutes. The DPPH radical scavenger activity was determined by using spectroscopy at $516 \mathrm{~nm}$ and compared with the DPPH solution as a control. Samples were tested in triplicate. Antioxidant activity was calculated as a percentage decrease in absorbance of the sample solution compared to the control. Antioxidant activity was determined using $\mathrm{IC}_{50}$ calculations.

\section{RESULTS AND DISCUSSION}

Curcuminoids fraction obtained from the ethanol extract of $C$. xanthorrhiza $(1 \mathrm{~kg})$ rhizome powder as much as $106 \mathrm{~g}(10.6 \%)$ are yellow-orange solids. Analysis using chromatography (TLC Scanner) with 
RASĀYAN J. Chem.

Vol. 13 | No. 2 |817 - 825| April - June | 2020

pure demethoxycurcumin as standard showed the presence of $20 \%$ demethoxycurcumin content in the curcuminoid fraction which was used further in this study. The curcumnioids are then used to make chitosan nanocurcuminoids and alginic nanocurcuminoids using ionic gelation methods, respectively. As a chitosan crosslinker Na-TPP is used, while for alginic are used calcium ions. In the study, variations in the concentration of each chitosan, Na-TPP, alginic, and calcium ions were used to obtain optimal products. Chitosan nanocurcuminoid products are bright yellow colloids, while alginic nanocurcuminoids are light brown colloids. Each colloid was then analyzed particle size, polydispersity index (PI), and zeta potential using Horiba SZ-100, for example, the data obtained in graphical form for the sample AK-1 is as shown in Fig.-1. The results of the analysis of each colloid obtained were then analyzed particle size, zeta potential, polydispersity index as listed in Tables- 1 and 2 .

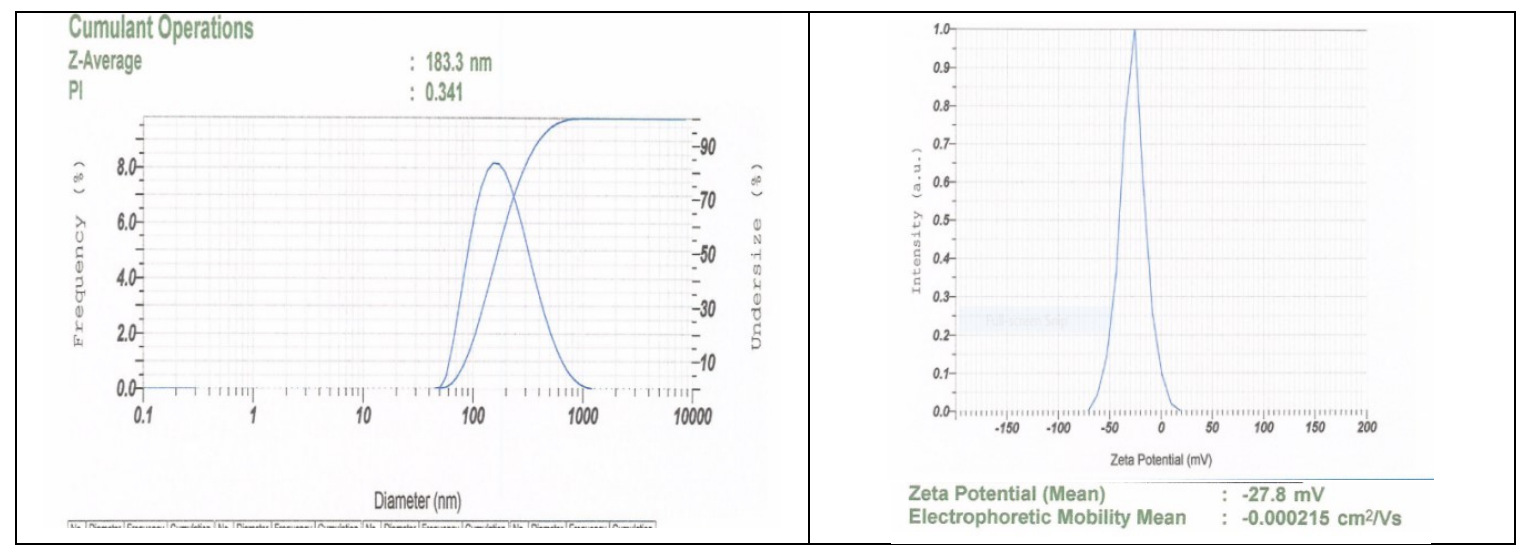

Fig.-1: Results of Particle Size Analysis (PAS), Polydispersity Index (PI), and Zeta Potential of Alginic Nanocurcumnoid (AK-1)

Table-1: Characteristic of Chitosan Nanocurcuminoid Product

\begin{tabular}{|c|c|c|c|c|c|c|c|c|c|c|}
\hline $\begin{array}{l}\text { Formula } \\
\text { Code }\end{array}$ & $\begin{array}{l}\mathrm{Cc} \\
(\mathrm{g})\end{array}$ & $\begin{array}{c}\text { Chito- } \\
\text { san } \\
(\% \\
\text { w/v) }\end{array}$ & $\begin{array}{l}\mathrm{Na}- \\
\mathrm{TPP} \\
(\% \\
\mathrm{w} / \mathrm{v}) \\
\end{array}$ & $\begin{array}{c}\% \\
\text { Nano } \\
\text { Parti- } \\
\text { cle }\end{array}$ & $\begin{array}{l}\text { Size } \\
(\mathrm{nm})\end{array}$ & $\begin{array}{c}\% \\
\text { Micro } \\
\text { Parti } \\
\text { cle }\end{array}$ & $\begin{array}{l}\text { Size } \\
(\mu \mathrm{m})\end{array}$ & $\begin{array}{c}\text { Z- } \\
\text { avera- } \\
\text { ge }(\mathrm{nm})\end{array}$ & PI & $\begin{array}{l}\text { Zeta } \\
\text { Poten- } \\
\text { sial } \\
(\mathrm{mV})\end{array}$ \\
\hline K1 & 0.1 & 0.1 & 0.01 & 54.10 & $\begin{array}{l}356.1- \\
945.74\end{array}$ & 45.9 & $\begin{array}{c}1068.52- \\
6667.14\end{array}$ & 836.8 & 0.230 & +22.3 \\
\hline K2 & 0.1 & 0.08 & 0.01 & 100.00 & $\begin{array}{l}93.02- \\
837.07\end{array}$ & 0.00 & - & 309.9 & 0.376 & +30.8 \\
\hline K3 & 0.1 & 0.06 & 0.01 & 94.52 & $\begin{array}{l}57.09- \\
945.74\end{array}$ & 5.48 & $\begin{array}{l}1068.52- \\
2511.05\end{array}$ & 251.8 & 0.299 & +30.01 \\
\hline K4 & 0.1 & 0.1 & 0.02 & 95.45 & 218.6 & 4.55 & $\begin{array}{c}1068.52- \\
1363.97\end{array}$ & 438.0 & 0.140 & +26.5 \\
\hline K5 & 0.1 & 0.1 & 0.04 & 45.27 & $\begin{array}{l}356.2- \\
945.74\end{array}$ & 54.73 & $\begin{array}{l}1068.52- \\
4622.81\end{array}$ & 823.2 & 0.285 & +25.3 \\
\hline K6 & 0.1 & 0.1 & 0.06 & 52.41 & $\begin{array}{l}356.2- \\
945.74\end{array}$ & 47.59 & $\begin{array}{l}1068.52- \\
5222.96\end{array}$ & 874.3 & 0.104 & +19.4 \\
\hline
\end{tabular}

*Cc $=$ Curcuminoid

Table-1 shows that the concentration of chitosan and Na-TPP used in the formulation affected the characteristics of the chitosan nanocurcuminoid formed. In the variation of the use of chitosan $0.08 \% \mathrm{w} / \mathrm{v}$ and Na-TPP $0.01 \% \mathrm{w} / \mathrm{v}$, chitosan nanocurcuminoid $(100 \%)$ was obtained with an average particle size (average Z) of $309 \mathrm{~nm}$, PI showed 0.376, and zeta potential $+30.8 \mathrm{mV}$. Another concentration variation obtained by nanocurcuminoids is less than 100 percent. The lowest percentage of chitosan nanocurcuminoid (45\%) in the variations in the use of chitosan $0.1 \% \mathrm{w} / \mathrm{v}$ and Na-TPP $0.06 \% \mathrm{w} / \mathrm{v}$. Thus, the comparison of the concentration of chitosan and Na-TPP will determine the chitosan 
RASĀYAN J. Chem.

nanocurcuminoid product obtained. Previous researchers have obtained a chitosan / Na-TPP ratio of 6: 1 obtained by nanoparticles with sizes in the range of 300-400 $\mathrm{nm}$ with a zeta potential in the range between +54 to $+25 \mathrm{mV}^{24}$. The size and composition of the nanoparticles obtained in addition to being determined by the chitosan / Na-TPP ratio used in the experiment were also influenced by the components in the extract and the type of chitosan used. Furthermore, the stability of nanoparticles is determined by the zeta potential which is a measure of the surface charge of nanoparticles in a solution or colloid. Nanoparticles have a surface charge that can attract particles with opposite charges. Zeta potential is the electrical potential in the surface layer that has typical values between $+100 \mathrm{mV}$ to $-100 \mathrm{mV}$. The potential of zeta nanoparticles with a value of more than $+25 \mathrm{mV}$ or less than $-25 \mathrm{mV}$ has a high level of stability. Colloids that contain a large percentage of nanoparticles will show a high zeta potential value so that it will be stable and difficult to form a precipitate ${ }^{25}$.

Table-2 showed that alginic nanocurcuminoid obtained more than $96 \%$ from this experiment with variations in the concentration of alginic acid and calcium ions used almost all of them can produce colloids with $\mathrm{Z}$ averages ranging from $161-298 \mathrm{~nm}$, PI 0.115 to 0.444 . The colloid also shows high stability with zeta potential value between $-12.8 \mathrm{mV}$ to $-27.8 \mathrm{mV}$. Therefore, a colloid of alginic nanoparticles at centrifugation of $12,000 \mathrm{rpm}$ did not get a precipitate, so that the characterization of nanoparticles in solid form, ie characterization using IR and SEM spectroscopy cannot be done.

The centrifugation of colloid from chitosan nanoparticle was carried out on all formulated samples, but the samples that could produce sediment were K2, K4, and K5, with dry sediment weight of 15 to $35 \mathrm{mg}$. Furthermore, from solid chitosan nanoparticles further analysis using IR spectroscopy and data obtained as shown in Fig.-2.

Table -2: Characteristic of Alginic Nanocurcuminoid Product

\begin{tabular}{|c|c|c|c|c|c|c|c|c|c|c|}
\hline $\begin{array}{l}\text { Formula } \\
\text { Code }\end{array}$ & $\begin{array}{l}\mathrm{Cc} \\
(\mathrm{g})\end{array}$ & $\begin{array}{l}\text { Algin } \\
\text { ic } \\
(\% \\
\mathrm{w} / \mathrm{v}) \\
\end{array}$ & $\begin{array}{l}\text { Na- } \\
\text { TPP } \\
(\% \\
\mathrm{w} / \mathrm{v}) \\
\end{array}$ & $\begin{array}{c}\% \\
\text { Nano } \\
\text { Parti- } \\
\text { cle }\end{array}$ & $\begin{array}{l}\text { Size } \\
(\mathrm{nm})\end{array}$ & $\begin{array}{c}\% \\
\text { Micro } \\
\text { Parti } \\
\text { cle }\end{array}$ & $\begin{array}{l}\text { Size } \\
(\mu \mathrm{m})\end{array}$ & $\begin{array}{c}\text { Z- } \\
\text { avera- } \\
\text { ge }(\mathrm{nm})\end{array}$ & PI & $\begin{array}{c}\text { Zeta } \\
\text { Poten- } \\
\text { sial } \\
(\mathrm{mV})\end{array}$ \\
\hline A-K-1 & 0.1 & 0.1 & 0.01 & 99.964 & $\begin{array}{l}50.53- \\
945.74\end{array}$ & 0.036 & 1068.52 & 183.3 & 0.341 & -27.8 \\
\hline $\mathrm{AK}-2$ & 0.1 & 0.1 & 0.015 & 97.813 & $\begin{array}{l}50.53- \\
945.74 \\
\end{array}$ & 2.187 & $\begin{array}{l}1068.52- \\
7532.65\end{array}$ & 210.4 & 0.240 & -22.1 \\
\hline AK-3 & 0.1 & 0.1 & 0.02 & 100 & $\begin{array}{l}57.05- \\
837.07\end{array}$ & 0 & - & 180.4 & 0.362 & -15.2 \\
\hline $\mathrm{AK}-4$ & 0.1 & 0.08 & 0.01 & 100 & $\begin{array}{l}57.09- \\
655.76\end{array}$ & 0 & - & 181.8 & 0.115 & -18.4 \\
\hline AK-5 & 0.1 & 0.06 & 0.01 & 100 & $\begin{array}{l}44.72- \\
655.76\end{array}$ & 0 & - & 161.6 & 0.362 & -19.8 \\
\hline AK-6 & 0.1 & 0.04 & 0.01 & 96.852 & $\begin{array}{l}39.58- \\
945.74\end{array}$ & 3.148 & $\begin{array}{c}1068.52- \\
6667.10\end{array}$ & 198.7 & 0.444 & -12.8 \\
\hline
\end{tabular}

$* \mathrm{Cc}=$ Curcuminoid

IR spectroscopy was carried out on chitosan, curcuminoid, chitosan nanocurcuminoid (K2, K4, and K5). The data shows that chitosan nanocurcuminoids have been successfully formulated. The absorption peak of chitosan nanocurcuminoids $\mathrm{K} 2, \mathrm{~K} 4$, and $\mathrm{K} 5$ show the combination of absorption of functional groups found in chitosan and curcuminoid. Curcuminoid extracted from $C$. xanthorrhiza usually contains curcumin and demethoxycurcumin, both of these compounds show almost the same IR spectrum characteristics. Absorption at wave number $1627 \mathrm{~cm}^{-1}$ indicates the presence of delocalized $\mathrm{C}=\mathrm{O}$ carbonyl groups and tends to form C-OH (enol), $1600-1400 \mathrm{~cm}^{-1}$ absorption characteristic of aromatic $\mathrm{C}=$ $\mathrm{C}$ groups. Chitosan nanocurcuminoid shows uptake as a combination of functional groups found in chitosan and curcuminoid. Morphological characterization of chitosan nanocurcuminoids using scanning electron microscopy (SEM) shows the morphology of chitosan nanoparticles K2, K4, and K5 which have a rounded surface shape (Fig.-3).

The results of the analysis of antioxidant activity using the DPPH (2,2-diphenyl-1-picrylhydrazyl) method from each chitosan nanocurcuminoid and alginic nanocurcuminoid solution were expressed as $\mathrm{IC}_{50} \mu \mathrm{g} /$ $\mathrm{mL}$ as shown in Table-3. Variations in the concentration of nanocurcuminoids and each tested colloidal 
RASĀYAN J. Chem.

Vol. 13 | No. 2 |817 - 825| April - June | 2020

solution tested for nanocurcuminoids were expressed as $\mathrm{IC}_{50} \mu \mathrm{g} / \mathrm{mL}$ as shown in Table-3 is $2.7,1.3,0.69$, $0.34,0.17$, and $0.086 \mu \mathrm{g} / \mathrm{mL}$. The data shows that chitosan and alginic nanocurminoids both have very active antioxidant activity. Chitosan nanocurcuminoid and alginic nanocurcuminoid show $\mathrm{IC}_{50}$ which is much lower than free curcuminoid, so it has higher activity. Thus it shows that curcuminoid in the form of nanoparticles is more effectively used as an antioxidant. This is caused in the form of nanoparticles which makes radical capture reactions easier. Chitosan nanocurcuminoid which have an average diameter of $215 \mathrm{~nm}$ showed the highest antioxidant activity $\left(\mathrm{IC}_{50}=0.07 \mu \mathrm{g} / \mathrm{mL}\right)$ and were more active than ascorbic acid $\left(\mathrm{IC}_{50}=1.27 \mu \mathrm{g} / \mathrm{mL}\right)$.

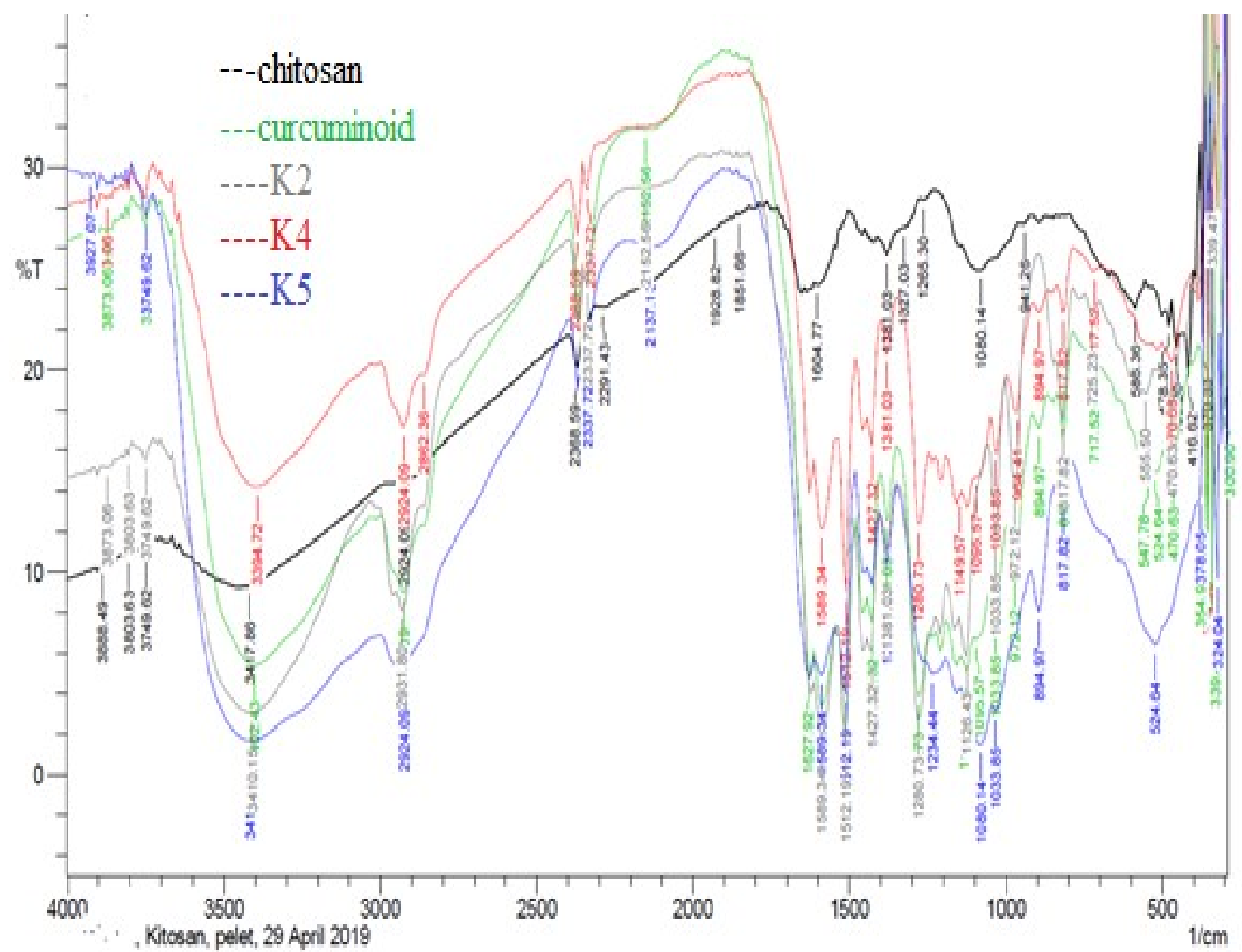

Fig.-2: FTIR Spectroscopy of Chitosan, Curcuminoid, Chitosan Nanocurcuminoid (K2, K4 and K5)

In this study the curcuminoid used was obtained from ethanol extract of $C$. xanthorrhiza which contained curcumin and demethoxycurcumin. Previous studies showed that curcumin encapsulated into methoxy poly (ethylene glycol) nanoparticles (cap-caprolactone) showed more effective anti-inflammatory activity and had a much higher absorption capacity (bioavailability) compared to curcumin powder ${ }^{26}$. Likewise, the curcumin encapsulation in PLGA and PEG shows higher efficacy and faster cellular absorption than the original curcumin by in vitro ${ }^{27}$. Curcuminoids in the form of nanoparticles have a larger surface area, so they can increase their reactivity in capturing radicals. Therefore nanocurcuminoids chitosan and nanocurcuminoid alginic show higher antioxidant activity compared to original curcuminoids. This is consistent with the results of previous studies that showed antioxidant activity using DPPH method from nanoparticle curcumin which showed higher activity than the original curcumin ${ }^{28}$.

Table-3: Antioxidant Activity of Chitosan Nanocurcuminoid and Alginic Nanocurcuminoid

\begin{tabular}{c|c|c|c}
\hline Sample & $\begin{array}{c}\text { Z-Average } \\
(\mathrm{nm})\end{array}$ & Regression Equation & $\begin{array}{c}\text { Antioxidant } \\
\text { Activity }\left(\mathrm{IC}_{50}\right) \\
\mu \mathrm{g} / \mathrm{mL}\end{array}$ \\
\hline $\begin{array}{c}\text { Chitosan Nanocurcuminoid: } \\
\text { K1 }\end{array}$ & 836.8 & $\mathrm{y}=19.848 \mathrm{x}+38.62$ & 0.57 \\
\hline
\end{tabular}

822 
RASĀYAN J. Chem.

Vol. 13 | No. 2 |817 - 825| April - June | 2020

\begin{tabular}{|c|c|c|c|}
\hline & & $\mathrm{R}^{2}=0.9446$ & \\
\hline K2 & 309.9 & $\begin{array}{c}\mathrm{y}=17.642 \mathrm{x}+43.754 \\
\mathrm{R}^{2}=0.9505\end{array}$ & 0.35 \\
\hline K3 & 251.8 & $\begin{array}{c}y=15.542 x+48.864 \\
R^{2}=0.9688\end{array}$ & 0.07 \\
\hline K4 & 438.0 & $\begin{array}{c}\mathrm{y}=10.748 \mathrm{x}+37.687 \\
\mathrm{R}^{2}=0.9952\end{array}$ & 1.14 \\
\hline K5 & 823.2 & $\begin{array}{c}y=15.379 x+1.0497 \\
R^{2}=0.9692\end{array}$ & 3.18 \\
\hline K6 & 874.3 & $\begin{array}{c}\mathrm{y}=9.7468 \mathrm{x}-4.639 \\
\mathrm{R}^{2}=0.9553\end{array}$ & 5.60 \\
\hline $\begin{array}{l}\text { Alginic Nanocurcuminoid: } \\
\text { AK1 }\end{array}$ & 183.3 & $\begin{array}{c}y=18.693 x+6.0382 \\
R^{2}=0.8498\end{array}$ & 2.35 \\
\hline AK2 & 210.4 & $\begin{array}{c}y=5.9706 x+0.6272 \\
R^{2}=0.8889\end{array}$ & 8.27 \\
\hline AK3 & 180.4 & $\begin{array}{c}\mathrm{y}=7.4119 \mathrm{x}+0.9018 \\
\mathrm{R}^{2}=0.8896\end{array}$ & 6.62 \\
\hline AK4 & 181.8 & $\begin{array}{c}\mathrm{y}=10.595 \mathrm{x}+9.0443 \\
\mathrm{R}^{2}=0.9197\end{array}$ & 3.86 \\
\hline AK5 & 161.6 & $\begin{array}{c}\mathrm{y}=9,1045 \mathrm{x}+11.25 \\
\mathrm{R}^{2}=0,8928\end{array}$ & 4.25 \\
\hline AK6 & 198.7 & $\begin{array}{c}\mathrm{y}=9.4007 \mathrm{x}+2.3268 \\
\mathrm{R}^{2}=0.8891\end{array}$ & 5.07 \\
\hline Curcuminoid & - & $\begin{array}{c}\mathrm{y}=1.0778 \mathrm{x}+23.099 \\
\mathrm{R}^{2}=0.9774\end{array}$ & 24.97 \\
\hline Ascorbic acid & - & $\begin{array}{c}\mathrm{y}=13.76 \mathrm{x}+32.51 \\
\mathrm{R}^{2}=0.883\end{array}$ & 1.27 \\
\hline
\end{tabular}

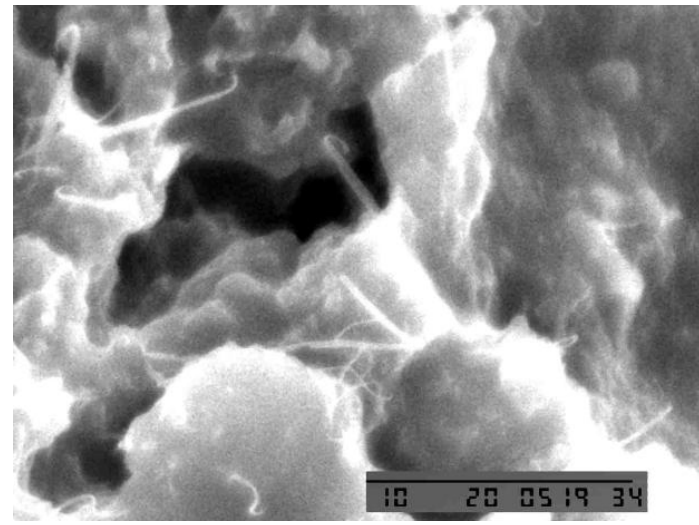

K2

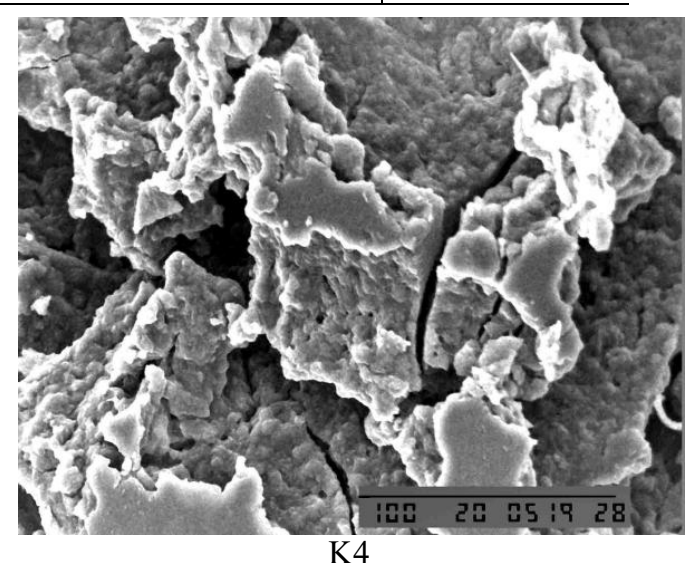

K4

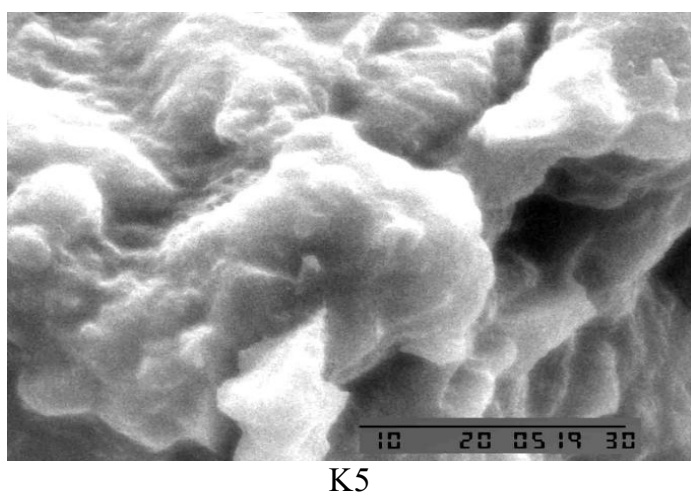

K5

Fig.-3: SEM Images of Chitosan Nanocurcuminoid of K2, K4, and K5 


\section{CONCLUSION}

Chitosan nanocurcuminoid and alginic nanocurcuminoid have been formulated using the ionic gelation method. Chitosan nanosurcuminoid have an average particle size (average Z) of $309 \mathrm{~nm}$, PI of 0.376, and zeta potential of $+30.8 \mathrm{mV}$, while alginic Nanocurcuminoids have an average particle size of 116.6 181.8, PI shows $0.115-0.362$, and zeta potential of -15.2-19.8 mV. Chitosan nanocurcuminoid and alginic nanocurcuminoid exhibit higher antioxidant activity compared to original curcuminoid. Chitosan nanocurcuminoid which have an average diameter of $215 \mathrm{~nm}$ showed the highest antioxidant activity $\left(\mathrm{IC}_{50}=0.07 \mu \mathrm{g} / \mathrm{mL}\right)$ and were more active than ascorbic acid $\left(\mathrm{IC}_{50}=1.27 \mu \mathrm{g} / \mathrm{mL}\right)$.

\section{ACKNOWLEDGMENT}

The author is very grateful for the research funding obtained from the Minister of Research and Technology of the Directorate of Higher Education, Indonesia in the scheme of basic research grant (2019).

\section{REFERENCES}

1. X.Y. Li, X.Y.Kong, S. Shi, X. Zheng, G. Guo, Y.Q. Wei, Z.Y. Qian, BMC Biotechnology, 8, 1 (2008), DOI:10.1186/1472-6750-8-89

2. E.C. Dreaden, L.A. Austin, M.A. Mackey, M.A. El-Sayid, Therapeutic Delivery, 3, 4(2012), DOI: $10.4155 /$ tde. 12.21

3. R. Ranganathan, S.Madanmohan, A. Kesavan, G. Baskar, Y. R. Krishnamoorthy, R. Santoshan, D. Ponraju, S.K. Rayala, G. Venkatraman, International Journal Nanomedicine, 7, 1043(2012), DOI: $10.2147 / \mathrm{IJN} . \mathrm{S} 25182$

4. A. Puri, K. Loomis, B. Smith, J.H. Lee, A. Yavlovich, E. Heldman. R. Blumenthal, Critical Reviews in Therapeutic Drug Carrier Systems, 26, 523(2009), DOI:10.1615/ critrevtherdrugcarriersyst.v26.i6.10

5. P. Desay, R. R. Patllola, M. Singh, Molecular Membran Biology, 27, 247(2010), DOI: 10.3109/09687688.2010.522203

6. W. Yan, Y. Wuli, W. Changchun, H. Jianhua, F. Shoukuan, International Journal of Pharmaceutics, 295, 235(2005), DOI:10.1016/j.ijpharm.2005.01.042

7. K. Mladenovska, O. Cruaud, P. Richomme, E. Belamie, R.S Raicki, M.C. Venier-Julienne, E. Popovski, J.P. Benoit, K. Goracinova, International Journal Pharmaceutic, 345, 59(2007), DOI: 10.1016/ j.ijpharm.2007.05.059

8. H. Itokawa, S. Qian, T. Akiyama, L. Susan, K.S. Lee, Chinese Medicine, 3, 1(2008), DOI: $10.1186 / 1749-8546-3-11$

9. M. Lechtenberg, B. Quandt, A. Nahrstedt, Phytochemical Analysis, 15, 152(2004), DOI: $10.1002 /$ pca. 759

10. B.B. Aggarwal, A. Kumar, A.C. Bhartic, Anticancer Research, 23, 363(2003).

11. T.H. Leu, M.C. Maa, Current Medicinal Chemistry: Anticancer Agents, 2, 357(2002), DOI: $10.2174 / 1568011024606370$

12. Y. Wu, Y. Chen, J. Xu, L. Lu, Zhonghua Zhong Liu Za Zhi, 24, 348(2002).

13. K. Kohli, J. Ali, M.J. Ansari, Z. Raheman, Indian Journal of Pharmacology, 37, 141 (2005), DOI: $10.4103 / 0253-7613.16209$

14. M. Shakibaei, T. John, G. Schulze-Tanzil, I. Lehmann, A. Mobasheri, Biochemical Pharmacology, 73, 1434(2007), DOI:10.1016/j.bcp.2007.01.005

15. S.Y Park, D.S Kim, Journal of Natural Product, 65, 1227(2002), DOI:10.1021/np010039x

16. Yuandani, S. Yuliasmi, D. Satria, R. F. Dongoran, M. S.sinaga, and N. H. A. Marpaung, Rasayan Jounal of Chemistry, 12, 1(2019), DOI:10.31788/RJC.2019.1215050

17. A. Asai, A. Miyasawa, The Journal of Nutrition, 131, 2932(2011), DOI:10.1093/jn/131.11.2932

18. M.B Kim, C. Kim, Y. Song, J.K.Hwang, Evidence-Based Complementary and Alternative Medicine, 2014, 1(2014), DOI: 10.1155/2014/205915.

19. P. Anand, A.B. Kunnumakkara, R.A. Newman, B.B Aggarwal, Molecular Pharmaceutics, 4, 807 (2007), DOI:10.1021/mp700113r 
RASĀYAN J. Chem.

Vol. 13 | No. 2 |817 - 825| April - June | 2020

20. R. Mulik, K. Mahadik, A. Paradkar, European Journal of Pharmaceutical Science, 28, 395(2009), DOI: 10.1016/j.ejps.2009.03.009

21. W. Tiyaboonchai, W. Tungpradit, P. Plianbangchang, International Journal of Pharmaceutics, 337, 299(2007), DOI:10.1016/j.ijpharm.2006.12.043

22. S. Atun S, S. Handayani, Pharmacognosy Journal, 9, 142(2017), DOI: 10.5530/pj.2017.2.24

23. M. Simorangkir, W. Hutabarat, B. Nainggolan and S. Silaban, Rasayan Journal of Chemistry, 12, 959(2019), DOI:10.31788/RJC.2019.1225095

24. S.A. Agnihotri, N.M. Nadagouda, M.A. Tejraj, Journal of Controlled Release, 100, 5(2004), DOI: 10.1016/j.jconrel.2004.08.010

25. K. Ronson, Nano Composix, 1, 1 (2012).

26. H. Sasaki, Y. Sunagawa, K. Takahashi, A. Imaizumi, H. Fukuda, T. Hashimoto, H.Wada, Y. Katanasaka, H. Kakeya, M. Fujita, K. Hasegawa, T. Morimoto, Biological \& Pharmaceutical Bulletin, 34, 660(2011), DOI:10.1248/bpb.34.660

27. P. Garodia, H. Ichikawa, N. Malani, G. Sethi, B.B. Aggarwal, Journal of The Society for Integrative Oncology, 5, 25 (2007), DOI:10.2310/7200.2006.029

28. M. Kakran, N.G. Sahoo, I.L. Tan, L. Li, Journal of nanoparticle Research, 14,1(2012), DOI: 10.1007/s11051-012-0757-0

[RJC-5860/2020] 